\title{
TYPE-DEPENDENT DIFFERENCE IN THE METABOLISM OF HUMAN HAPTOGLOBINS
}

\author{
Kazunori Tsuda-Kawamura, * Akira Ogawa, * \\ Nobuyoshi Tachibana, * Hideo OHokubo,** Katsunori Shibata, ** \\ and Toshiyuki YANASE** \\ *The Second Department of Medicine, Miyazaki Medical College, Miyazaki \\ **The First Department of Medicine, Faculty of Medicine, \\ Kyushu University, Fukuoka
}

Summary Metabolic properties of haptoglobin 1-1 and 2-2 proteins were investigated by performing turnover studies in normal rabbits in a steady state concerning haptoglobin metabolism. Studies in six rabbits showed that the average plasma half-lives of iodinated haptoglobin 1-1 and 2-2 were similar with values of 2.3 and 2.4 days, respectively. The distribution in the body compartments, however, was significantly different at the equilibrium time and was such that the extravascular compartments contained $57.0 \%$ of the total body pool of haptoglobin 1-1, compared only $36.9 \%$ in the case of haptoglobin $2-2$. These findings suggest that the former protein is higher than the latter in capillary permeability.

These phenomena may be attributable to the difference in the molecular size and/or polymeric structure rather than that in the primary structure between two haptoglobins. The present results would reflex the survival of human haptoglobins in normal man, although the results were obtained by tracing human haptoglobins injected in rabbits. Finally, the biological significance of the type-dependent metabolism of haptoglobins was discussed.

\section{INTRODUCTION}

Haptoglobin has a specific capacity to bind hemoglobin and has recently been noted as a representative of acute phase reactive proteins (Snellman and Sylvén, 1967; Jayle et al., 1970; Sutton, 1970). The authors (Ogawa and Kawamura, 1966; Kawamura et al., 1973) and Füller et al. (1973) have reported the molecular structure of haptoglobins of three types. Several metabolic features have been demonstrated by turnover studies using radioiodinated haptoglobins administered to man and laboratory animals of physiological and of a variety of pathological states (Moretti et al., 1963; Freeman, 1964; Krauss et al., 1966; Ohara et al., 1968; Krauss, 1969; Borel et al., 1963).

Received January 5, 1979 
The metabolic properties of plasma protein components are known to be related in part to their molecular sizes and/or polymeric structures, but the typedependent difference of molecular structure among haptoglobins has not been taken into consideration in the previous metabolic studies. The present communication is concerned with the comparative studies on the survival of radioiodinated human haptoglobin 1-1 and 2-2 injected in rabbits.

\section{MATERIALS AND METHODS}

Isolation and radioiodination of haptoglobins. Human haptoglobins of types 1-1 and 2-2 were isolated from normal donor plasma by chromatography on a DEAE-cellulose column as reported previously (Ogawa and Kawamura, 1966). After rechromatography on the same column, the preparations were further purified by ammonium sulfate fractionation followed by several dialyses against distilled water. All the procedures were carried out at $4^{\circ} \mathrm{C}$.

The proteins were labeled with either ${ }^{131} \mathrm{I}$ or ${ }^{125} \mathrm{I}$ by the iodine monochloride method of McFarlane (1958). The specific activity was $100 \mu \mathrm{Ci}$ per mg protein at the preparation, and all preparations contained less than 1 to $3 \%$ nonprecipitable radioactivity. Following the labeling, mixtures of haptoglobins of two types were prepared containing $10 \mu \mathrm{Ci}$ of ${ }^{131} \mathrm{I}$ and $10 \mu \mathrm{Ci}$ of ${ }^{125} \mathrm{I}$ per $\mathrm{ml}$ in phosphate-buffered $0.12 \mathrm{M}$ saline solution, $\mathrm{pH}$ 7.2. Rabbit albumin ( $30 \mathrm{mg}$ per $\mathrm{ml}$ ) was added to prevent damage of the haptoglobins by self-irradiation and labeled preparations were stored at $4^{\circ} \mathrm{C}$ and were injected into animals within 3 days after iodination.

Turnover study protocol. Male rabbits weighing 2.0 to $2.5 \mathrm{~kg}$ were fed Purina Chow in metabolic cages. They were given water containing $0.01 \%$ potassium iodide solution daily, beginning 3 days prior to the injection of isotopes and continuing throughout the study periods to prevent thyroid uptake of the liberated isotopes. A pair of labeled preparation was injected into ear vein of animals: $10 \mu \mathrm{Ci}$ of one preparation labeled with ${ }^{131} \mathrm{I}$ and $10 \mu \mathrm{Ci}$ of the other with ${ }^{125} \mathrm{I}$.

A 10-min blood sample was drawn for plasma volume determination and subsequent bleeding were made daily for 9 days following the injection. Twenty-four-hr urine collections were obtained with care in order to avoid cumulative errors in the calculation arising from possible incomplete urine collections. Heparinized blood and urine samples were centrifuged and the radioactivity of $1.0 \mathrm{ml}$ aliquots was counted with appropriate standards in an automatic gamma-ray well-type scintillation counter with a thalium-activated sodium iodide crystal. A pulse height analyser allowed differentiation of the two isotopes in the samples.

Calculation of the metabolic data. The data were analyzed according to the method of Andersen (1964). Plasma volume was calculated on the basis of initial distribution of the administered radioactivity of haptoglobin 2-2, using the specific activity of the $10-\mathrm{min}$ plasma sample. Plots were constructed on semi logarithmic papers of the plasma radioactivity and of the remaining total body activity as plotted 
a

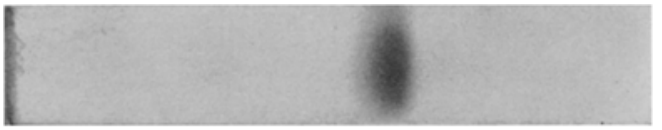

b

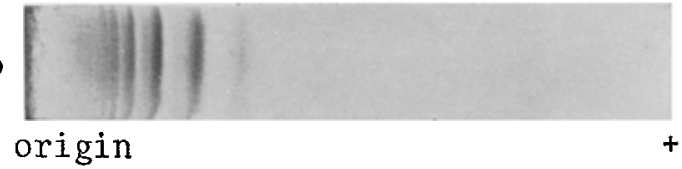

Fig. 1. Electrophoretic patterns in $7.5 \%$ acrylamide gel of (a) isolated haptoglobin 1-1 and (b) isolated haptoglobin 2-2. Electrophoresis was performed as described in the text and gel was stained with Amidoblack 10B.

against time. Total body activity was calculated by cumulative subtraction of radioactivity excreted in urine from that originally administered. The proportion of administered radioiodinated haptoglobins which distributed extravascular, after equilibration with the intravascular spaces was complete, was calculated from the intravascular and total body activity. Fraction intravascular after equilibration= counts per min per ml plasma $\times$ plasma volume $(\mathrm{ml}) /$ counts per min remaining in the whole body. The data were analyzed and compared using the significance of the difference of the means.

Electrophoresis. The hemoglobin-binding capacity of rabbit plasma and isolated haptoglobin preparations was determined by the electrophoretic method of Colfs and Verheyden (1965). Acrylamide disc gel electrophoresis and cellulose acetate membrane electrophoresis were performed as reported previously (Ogawa and Kawamura, 1966).

\section{RESULTS}

\section{Preparation of radioiodinated haptoglobin preparations}

Purity of the isolated haptoglobins was assessed by electrophoresis on acrylamide gel (Fig. 1) and cellulose acetate membrane at alkaline pH. Haptoglobin 1-1 gave a single band, but haptoglobin 2-2 was contaminated with 2 to $3 \%$ of plasma proteins, most of which was serum albumin. The quantitative ratio of hemoglobincomplexes of haptoglobin 2-2 bands on acrylamide gel was not significantly different between the plasma haptoglobin 2-2 and isolated haptoglobin 2-2 preparations, indicating that the relative amount of haptoglobin 2-2 proteins was not altered during the purification procedure.

Furthermore, the hemoglobin-binding capacity and electrophoretic behavior on acrylamide gel and cellulose acetate membrane of haptoglobins before and after the iodination with ${ }^{131} \mathrm{I}$ or ${ }^{125} \mathrm{I}$ were ascertained to be unchanged, indicating that labeled haptoglobins apparently remained unaltered. 

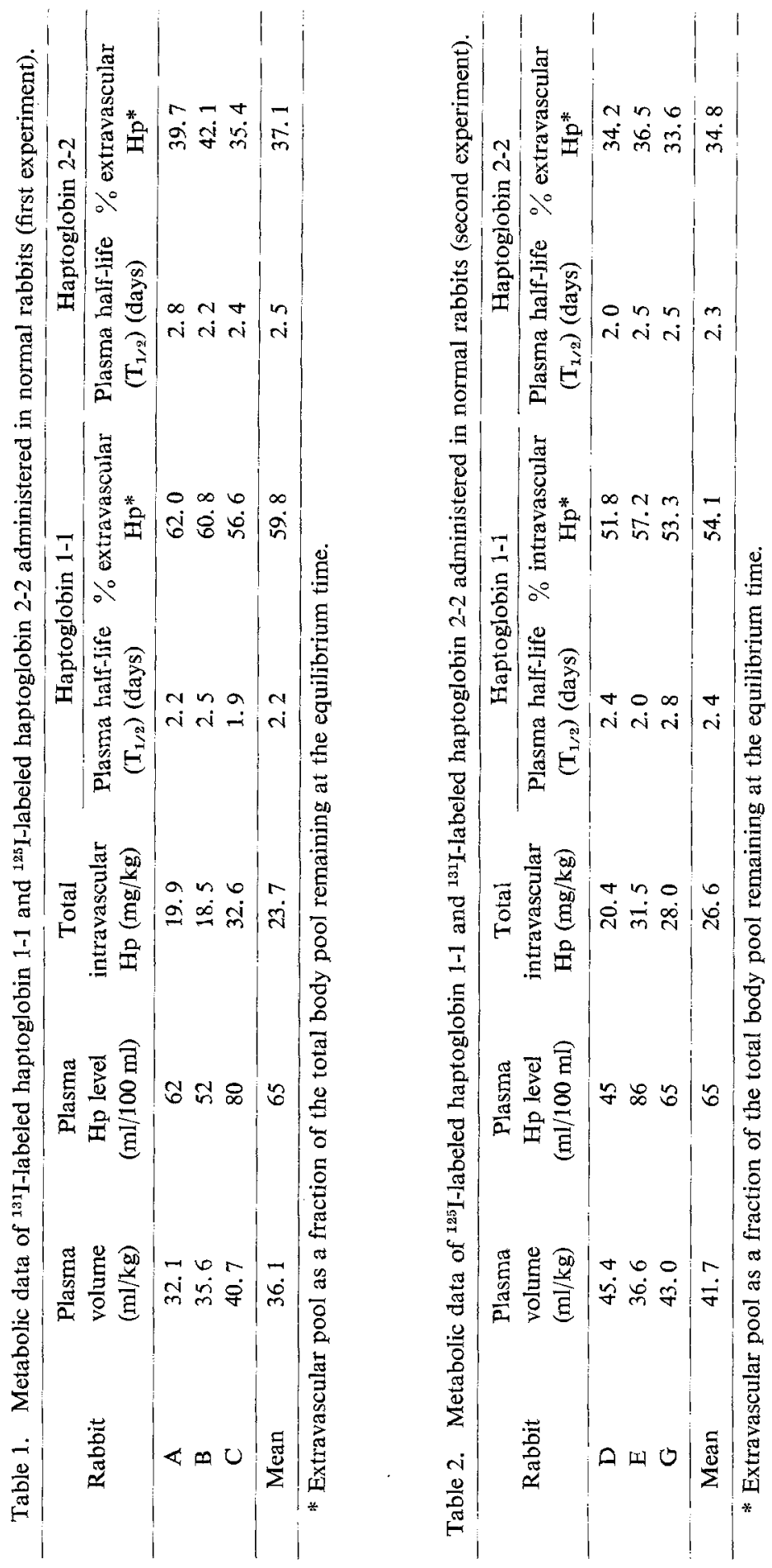

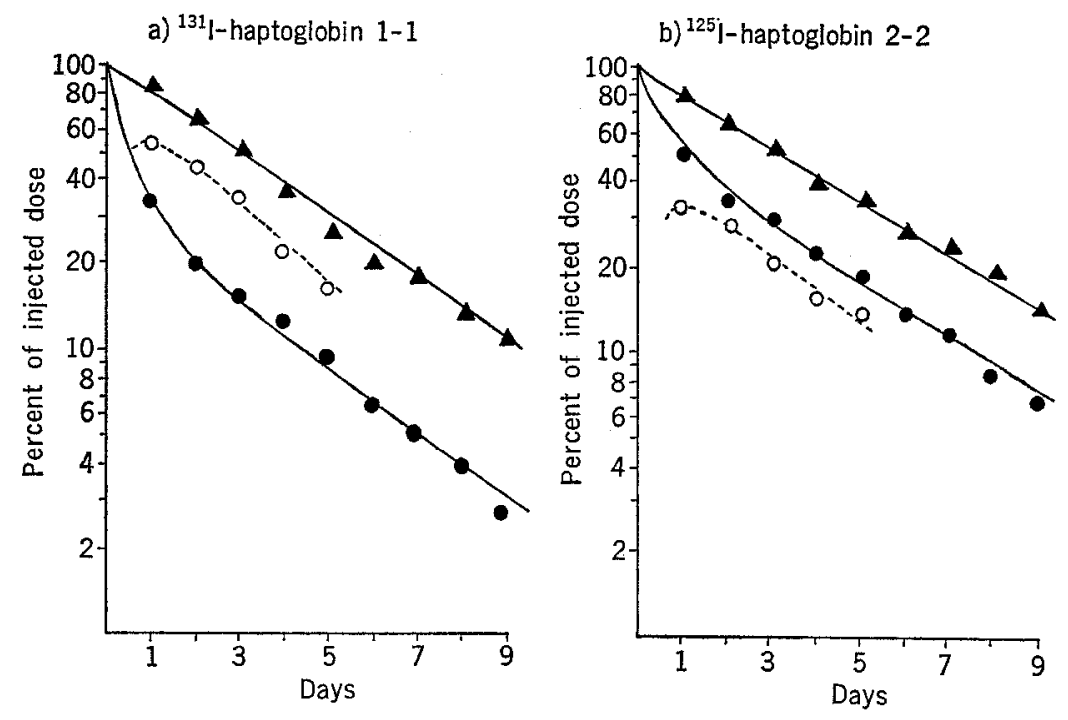

Fig. 2. Plots of intravascular ( $)$, extravascular $(0)$, and total body (A) radioactivity in rabbit $\mathrm{A}$. A pair of ${ }^{131} \mathrm{I}$-haptoglobin $1-1(10 \mu \mathrm{Ci})$ and ${ }^{125} \mathrm{I}$ haptoglobin 2-2 $(10 \mu \mathrm{Ci})$ was injected and the plasma half-life time were calculated as 2.2 and 2.8 days, respectively. Note that $62.0 \%$ of the total body radioactivity of haptoglobin $1-1$ is extravascular, while only $39.7 \%$ in the case of haptoglobin 2-2 at the equilibrium time.

\section{Metabolic studies of labeled haptoglobins}

In order to minimize the individual variations in the metabolic data, haptoglobin 1-1 and 2-2 were separately labeled with either ${ }^{131} I$ or ${ }^{125} I$, injected together and their survivals were compared directly in the same animals. Two sets of experiments were performed according to the following designs:

The first set of experiments was carried out in three rabbits, and the results are given in Table 1 and Fig. 2. Rabbit $\mathrm{A}, \mathrm{B}$, and $\mathrm{C}$ received a mixture containing $10 \mu \mathrm{Ci}$ of ${ }^{131}$ I-haptoglobin $1-1$ and $10 \mu \mathrm{Ci}$ of ${ }^{125}$ I-haptoglobin $2-2$ preparations.

Plasma elimination curves of both proteins, plotted on a semi logarithmic scale, showed the usual initial decrease probably associated with the mixing of proteins between intra- and extra-vascular compartments. This phase was followed after 4 to 9 days by an apparently linear rate of decrease representing catabolism of injected haptoglobins. The biological half-lives of haptoglobins showed considerable variation when studied in different animals (Table 1). The mean values, however, were similar for the both proteins, and 2.2 days for haptoglobin 1-1 and 2.5 days for haptoglobin 2-2. The total body radioactivity of haptoglobin 1-1 declined showing a slop of the curve similar to that of haptoglobin 2-2.

The distribution of labeled haptoglobins in the body compartments was estimated from data of plasma and urine radioactivity. Extravascular activity of both proteins 
Table 3. Summary of metabolic studies on radioiodinated haptoglobin 1-1 and haptoglobin 2-2 injected in normal rabbits

\begin{tabular}{lccc}
\hline & $\begin{array}{c}\text { Number of } \\
\text { rabbit }\end{array}$ & $\begin{array}{c}\text { Plasma half-life } \\
\left(\mathrm{T}_{1 / 2}\right) \text { (days) }\end{array}$ & $\begin{array}{c}\% \text { extravascular } \\
\mathrm{Hp}^{*}\end{array}$ \\
\hline Haptoglobin 1-1 & 6 & $2.3 \pm 0.3$ & $57.0 \pm 3.4$ \\
Haptoglobin 2-2 & 6 & $2.4 \pm 0.3$ & $36.9 \pm 3.0$ \\
\hline
\end{tabular}

* Extravascular pool as a fraction of the total body pool remaining at the time of equilibrium.

increased rapidly and reached a maximum value by $24 \mathrm{hr}$ after the injection, indicating that equilibrium between intra- and extra-vascular compartments is usually completed within $24 \mathrm{hr}$ following injection of both haptoglobins. At the equilibrium point, indicated by the highest value on the plot of extravascular activity, the proportion of radioactivity in intra- and extra-vascular compartments was different between the two proteins. $59.8 \%$ of the total body activity of haptoglobin 1-1 was distributed extravascularly, while only $37.1 \%$ was extravascular in case of haptoglobin 2-2.

The second set of experiments was performed by injecting ${ }^{125}$ I-haptoglobin $1-1$ and ${ }^{131} \mathrm{I}$-haptoglobin 2-2 proteins, radioiodinated with opposite types of isotope to the preceding study. Rabbit D, E and $\mathrm{G}$ received a mixture containing $10 \mu \mathrm{Ci}$ of each labeled protein and the metabolic data are given in Table 2.

The slopes and configurations of the plasma and total body radioactivity of the two proteins were similar to these obtained in the preceding experiments. The biological half-life time of haptoglobin 1-1 and 2-2 were similar with value of 2.4 and 2.3 days, respectively. However, per cent of distribution of haptoglobin 1-1 and $2-2$ into the extravascular compartments were different, comprising 54.1 and $34.8 \%$ of the total body activity at the equilibrium time, respectively.

The metabolic behavior, half-life times and configurations of the plasma and total body radioactivity curves of haptoglobins labeled with ${ }^{131} \mathrm{I}$ and ${ }^{125} \mathrm{I}$ were similar each other in both types, the data obtained in two experiments therefore have been combined.

The mean values obtained in the both experiments are given in Table 3 . The biological half-lives were calculated to be 2.3 and 2.4 days for haptoglobin $1-1$ and $2-2$, respectively. But the distribution of injected radioactivity in the body compartments was significantly $(\mathrm{P}<0.01)$ different between the two haptoglobins. Only about $36.9 \%$ of the total body pool of haptoglobin $2-2$ lied in the extravascular space, the rest remaining intravascular at the equilibrium time. In contrast, about $57.0 \%$ of haptoglobin 1-1 was extravascular at the equilibrium point. The fractional catabolic rate, representing that fraction of the average daily plasma radioactivity excreted into the urine during that interval, was similar in animals injected the heptoglobins of same types.

The slopes of the plasma and total body radioactivity curves did not change significantly 4 to 9 days following the injection, indicating that no immune elimination 
of haptoglobins occurred. Furthermore, the plasma concentrations of haptoglobins remained constant during the study periods, all animals therefore may be assumed to be in a steady state concerning haptoglobin metabolism.

\section{DISCUSSION}

The authors have isolated and physically characterized the hemoglobin complexes of three major haptoglobin 2-1 polymers. From these results and extension of earlier observations (Ogawa and Kawamura, 1966; Sutton 1970), the authors proposed a molecular representation of haptoglobin 2-1 proteins as $(\alpha \beta)_{2}{ }^{\mathrm{Hp} 2-1},(\alpha \beta)_{3}{ }^{\mathrm{Hp} 2-1}$, $(\alpha \beta)_{4}{ }^{\mathrm{Hp} 2-1}, \ldots \ldots$ By analogy, the haptoglobin $2-2$ polymers would be $(\alpha \beta)_{3}{ }^{\text {Hp2-2 }}$, $(\alpha \beta)_{4}{ }^{\mathrm{Hp} 2-2},(\alpha \beta)_{5}{ }^{\mathrm{Hp} 2-2} \ldots$ (Kawamura et al., 1973). Füller et al. (1973) have isolated and extensively characterized the haptoglobin 2-2 polymers and concluded that each polymer differs from the next number of the series by an average increment 545,000 of molecular weight, approximating an $\left(\alpha^{2} \beta\right)$ subunit. The average molecular weights of haptoglobin 2-1 and 2-2 proteins, calculated from their polypeptide compositions, are approximately two to three-fold larger than that of haptoglobin $1-1,\left(\alpha^{1} \beta\right)_{2}$. It may be said therefore that haptoglobin is a peculiar type of polymorphic variants in the sense that differences reside not only in the primary structure of the $\alpha$-chains (Black and Dixon, 1968), but also in the polymeric structure and molecular size among haptoglobins of three types.

Several investigators (Moretti et al., 1963; Freeman, 1964, Krauss et al., 1966; Ohara et al., 1968; Krauss, 1969) have studied the metabolism of human haptoglobins. But they have not taken the genetic types of haptoglobins into consideration, and comparative study on the survival of haptoglobins of different types in normal man has not been reported so far.

Radioiodinated haptoglobin 1-1, and 2-2, the products of the homozygotes of $H p^{1}$ and $H p^{2}$ genes, were therefore injected simultaneously in rabbits and their metabolism were compared directly in the same animals. The observed biological half-lives $\left(\mathrm{T}_{1 / 2}\right)$ of haptoglobin 1-1 and 2-2 were similar with values of 2.3 and 2.4 days, respectively, and these values were almost in accord with the results previously obtained in normal man and rabbit (Borel et al., 1963). A relationship between a progressively increasing degree of polymerization and a correspondingly shorter half-life has been indicated for albumin (Bocci, 1967), but no significant difference was observed in the half-life between two haptoglobins.

However, the distribution of injected radioactivity in the body compartments was significantly different between two proteins. The results that the larger molecules remain intravascular is compatible with a hypothesis that normal passage of plasma proteins out of the intravascular compartment involves transit through pores or other structures of a limiting size. Evidence for this has been reported from the studies of other plasma proteins (Barth et al., 1964; McFarlane, 1963; Berson et al., 1953; Awai and Brown, 1963). 
Although the mechanism responsible for this type-dependent difference of distribution in the body compartments must await for further studies, a plausible explanation for this probably is that the difference is related to the difference in the molecular size and/or polymeric structure between two proteins, rather than that in the primary structure between $\alpha^{1}$ and $\alpha^{2}$ chains of haptoglobins (Black and Dixon, 1968). As described above, haptoglobin 2-2 proteins consist of more than ten polymers and the molecular weights are markedly different, ranging approximately 170,000 to more than 600,000 , among haptoglobin $2-2$ molecules. The present results are therefore the average values of haptoglobin 2-2 molecules. The smaller molecules of haptoglobins 2-2 could enter into the extravascular compartments more easily than the larger molecules, although the experiment with the each isolated polymer of haptoglobin proteins is necessary. By analogy, furthermore, haptoglobin 2-1 proteins, the product of the heterozygote of $\mathrm{Hp}^{1}$ and $\mathrm{Hp}^{2}$ genes and has the intermediary molecular size, would have the intermediate metabolic properties between haptoglobin 1-1 and 2-2.

The metabolic studies of radioiodinated haptoglobin 2-1 proteins injected in normal person by Krauss (1969) showed the extravascular mass was only about onethird of the plasma mass at the equilibrium time. Freeman (1964) reported that in normal man approximately half of the radioactivity went into the extravascular spaces in the case of haptoglobin 1-1. On the other hand, it has been posturated from the comparative analysis of electrophoretic patterns of haptoglobins in plasma and cerebrospinal fluid or urine which seem to be derived from plasma (Sutton, 1970), that haptoglobins with smaller molecular weight could enter the cerebrospinal fluid (Blau et al., 1963), or be eliminated with the urine (Harris et al., 1960; Berggard and Bearn, 1962) more easily than haptoglobins of higher molecular weight. These findings will be compatible with the present results that the capillary permeability of haptoglobins seems to be related to their molecular sizes.

Under physiological condition, it is estimated that about 20 to $40 \%$ of the haptoglobin catabolized daily is degradated via complex with hemoglobin released during normal intravascular hemolysis (Freeman, 1964; Noyes and Garby, 1967). The hemoglobin-haptoglobin complex, once formed, is cleared rapidly from the circulation with a half-life of 9 to $30 \mathrm{~min}$ (Freeman, 1964). Free haptoglobin is catabolized by another, slower route, similar, perhaps, to that by which other plasma proteins are catabolized. Thus the disappearance curve of radioionated haptoglobins is the resultant of both catabolic process. Plasma haptoglobin levels, however, were found to be unchanged during the periods of experiments, indicating that rabbits were in a steady state concerning haptoglobin metabolism.

Although the present data were obtained by tracing human haptoglobins, that is heterologous haptoglobins, injected into the rabbits, the slopes of the plasma and total body activity curves did not change significantly 4 to 9 days following injection, indicating that no immune elimination of haptoglobins occurred. The results obtained here would reffect the distribution of haptoglobins in the body compart- 
ments of normal person, since it has been known that the capillary barriers of normal rabbit to plasma proteins are not significantly different from those of normal person.

The biological significance of the type-dependent difference in haptoglobin metabolism is obscure at the present time, since the function of haptoglobin is still somewhat uncertain. Haptoglobin is a representative of acute phase reactive proteins and plasma haptoglobin levels increase as a result of increased hepatic synthesis in a variety of diverse pathologic states, such as infection, experimentally induced inflammatory states, traumas and neoplasmas, characterized by breakdown, repair or proliferation of tissues with or without hemolysis. Whether the hemoglobin-binding is the sole function has not been established, but there are suggestions of some functions in the extravascular compartments concerning with these pathological states (Snellman and Sylvén, 1967; Moretti and Jayle, 1965; Jayle et al., 1970).

Haptoglobin appear to be synthesized exclusively in the liver and most, if not all, of the newly synthesized haptoglobin is released into the circulation. The present data demonstrated that smaller molecules of haptoglobins are able to get into the extravascular compartments more easily. It may be that some functions there can be more easily carried out by haptoglobin 1-1 protein than haptoglobin 2-2 molecules as suggested by Sutton (1970). Plasma haptoglobin levels decrease in a variety of pathologic states, especially in chronic liver diseases and malnutrition probably due to its decreased hepatic synthesis, and in conditions with increased intravascular hemolysis due to its increased catabolism (Krauss, 1969). In these pathological states, it may be that the reduction in the extravascular haptoglobin level, probably in pararell with the decrease in plasma levels, would be more prominent than that in normal condition and some function of haptoglobin in the extravascular areas could not be carried out efficiently in the case of haptoglobin 2-2. Comparative studies on the distribution and uptake of haptoglobins of different types in various organs or tissues of rats are now in progress in the author's laboratory.

Acknowledgment The authors are greatly indebted to professor H. E. Sutton, University of Texas at Austin, for his critical reading of the manuscript prior to submission.

\section{REFERENCES}

Andersen, T. B. 1964. Metabolism of Human Gamma Globulin, Blackwell Scientific Publications, Oxford, pp. 9-30.

Awai, M. and Brown, E. B. 1963. Studies on the metabolism of ${ }^{131}$ I-labeled human transferrin. J. Lab. Clin. Med. 61: 363-396.

Barth, W. F., Wochner, R. D., Waldmann, T. A., and Fahey, J. L. 1964. Metabolism of human gamma macroglobulins. J. Clin. Invest. 43: 1036-1048.

Berggard, I. and Bearn, A. G. 1962. Excretion of haptoglobin in normal urine. Nature 195: 1311-1312.

Berson, S. A., Yalow, R. S., Schreiber, S. S., and Post, J. 1953. Tracer experiments with ${ }^{131}$ Ilabeled human serum albumin: Distribution and degradation studies. J. Clin. Invest. 32: 746-768. 
Black, J. A. and Dixon, G. H. 1968. Amino acid sequence of the alpha chains of human haptoglobins and their possible relation to the immunoglobulin light chains. Nature 218: 736-741.

Blau, J. N., Harris, H., and Robson, E. B. 1963. Haptoglobins in cerebrospinal fluid. Clin. Chim. Acta 8: 202-206.

Borel, J., Dobryszycka, W., Moretti, J., and Jayle, M.-F. 1963. Vitesse de renouveliement de l'haptoglobine Plasmatique chez 'le lapin. Bull. Soc. Chim. Biol. 45: 203-210.

Colfs, B. and Verheyden, J. 1965. A rapid method for the determination of serum haptoglobin. Clin. Chim. Acta 12: 470-472.

Freeman, T. 1964. Haptoglobin metabolism in relation to red cell destruction. In: Proc. XII Colloq. Proteides Biol. Fluids. Elsevier, Amsterdam, pp. 344-352.

Füller, G. M., Rasco, M. A., McCombs, M. L., Barnett, D. R. and Bowman, B. H. 1973. Subunit composition of haptoglobin 2-2 polymers. Biochemistry 12: 253-258.

Harris, H., Penington, D. G., and Robson, E. B. 1960. Electrophoresis of plasma proteins in starch gels. Biochem. J. 74: 44.49.

Jayle, M.-F., Janiaud, P., Engler, R., Degrelle, H. and Marcais, J. 1970. Incorporation of the APR sialoglycoproteins in granulomatous tissues. In: Proc. XVIII Colloq. Proteides. Biol. Fluids. Pergamon Press, Oxford, pp. 159-162.

Kawamura, K., Ogawa, A., Kagiyama, S., and Yanase, T. 1973. Physical characterization of human haptoglobin polymers. in publication.

Krauss, S. 1969. Haptoglobin metabolism in polycythemia vera, Blood 33: 865-876.

Krauss, S., Schrott, M., and Sarcione, E. J. 1966. Haptoglobin metabolism in Hodgkin's disease. Am. J. Med. Sci. 252: 184-191.

McFarlane, A. S. 1958. Effective trace-labelling of proteins with iodine. Nature 182: 53.

McFarlane, A. S. 1963. In vivo behavior of ${ }^{131}$ I-fibrinogen. J. Clin. Invest. 42: 346-361.

Moretti, J., Borel, J., Dobryszycka, W., and Jayle, M.-F. 1963. Determination de la demi-vie de l'haptoglobine plasmatique humaine. Biochim. Biophys. Acta 69: 205-211.

Moretti, J. and Jayle, M.-F. 1965. Sur le role biologique de haptoglobine. C. R. Acad. Sci, 261: 1435-1438.

Noyes, W. D. and Garby, L. 1967. Rate of haptoglobin synthesis in normal man. Scand. J. Clin. Lab. Invest. 20: 33-38.

Ogawa, A. and Kawamura, K. 1966. The binding mechanism of haptoglobin with hemoglobin. I. Proc. Japan Acad. 42: 413-417.

Ohara, H., Watanabe, K., and Wada, T. 1968. Turnover rate of serum haptoglobin in malignant neoplastic diseases. Clin. Chim. Acta 19: 41-47.

Snellman, O. and Sylvén, B, 1967. Haptoglobin acting as a natural inbibitor of cathepsin B activity. Nature 216: 1033.

Sutton, H. E. 1970. The haptoglobins. Prog. Med. Genet. 7: 163-216. 